\title{
Prototipe Peringatan Dini Banjir dengan Menerapkan Teknologi Internet of Thing
}

\author{
Supriadi $^{\# 1}$, Agusma Wajiansyah ${ }^{\# 2}$, Arief Bramanto Wicaksono Putra ${ }^{\# 3}$ \\ \#Jurusan Teknologi Informasi,Politeknik Negeri Samarinda \\ Kampus Gunung Panjang, Jl. Ciptomangunkusumo Samarinda Seberang - Samarinda, KalTim \\ ${ }^{1}$ supriadi.polnes@gmail.com \\ 2agusma.wajiansyahegmail.com \\ ${ }^{3 *}$ ariefbramegmail.com
}

\begin{abstract}
Abstrak - Salah satu dampak nyata dari perubahan iklim adalah banjir yang telah terjadi lebih sering di banyak wilayah padat penduduk dan menyebabkan dampak pada kehidupan manusia dan mata pencaharian. Tujuan penelitian ini adalah membangun algoritma untuk memudahkan seseorang atau pengguna dapat mengetahui kondisi dan mendapat peringatan tentang ketinggian permukaan air terhadap permukaan jalan raya. Pengguna dapat memonitor ketinggian air dengan menggunakan smartphone apabila ketinggian permukaan air kanal dibawah permukaan jalan, dan pengguna akan mendapat peringatan apabila tiba-tiba permukaan air meningkat melebihi permukaan jalan secara real time. Untuk medapatkan ketinggian permukaan air kanal, dengan cara memanfaatkan rambatan gelombang suara ultrasonit yang dipantulkan pada obyek. Dengan diketahuinya jarak obyek, maka dapat dilakukan komputasi untuk mengetaui ketinggian permukaan air kanal. Nilai ketinggian permukaan air kanal dikrim melalui jaringan internet menuju Internet of Thing (IoT) cloud server yang dapat di monitor oleh pengguna. Sedangkan nilai ketinggian permukaan air kanal yang tidak normal akan menjadi keputusan untuk memberi interupsi peringatan kepada pengguna, apabila pengguna sedang tidak dalam keadaan sedang memantau. Hasil percobaan pada prototipe ini mampu memberikan representasi variabel ketinggian permukaan air dalam bentuk grafis dan nilai numerik, serta mampu memberi peringatan pada pengguna melalui smartphone. Sistem peringatan dini banjir mampu merepresentasikan data dalam bentuk level vertikal dan data numerik dengan tinggkat ketinggian air paling rendah adalah $-150 \mathrm{~cm}$ dan paling tinggi $130 \mathrm{~cm}$, dengan representasi nilai 0 cm apabila tingkat ketinggian permukaan air sejajar dengan permukaan badan jalan. Interupsi peringatan muncul apabila nilai tingkat ketinggian air lebih dari $0 \mathrm{~cm}$.
\end{abstract}

Kata kunci- Banjir, IoT, Sensor, Ketinggian Air, Ultrasonic

\section{Pendahuluan}

Perubahan iklim telah menjadi masalah serius yang menarik minat banyak peneliti dalam beberapa tahun terakhir. Salah satu dampak nyata dari perubahan iklim adalah banjir yang telah terjadi lebih sering di banyak wilayah dan menyebabkan dampak pada kehidupan manusia dan mata pencaharian. Banyak peringatan banjir telah dikembangkan dan dipasang di beberapa negara tetapi biaya manufaktur biasanya terlalu tinggi untuk praktis di negara berkembang. Oleh karena itu, membangun sistem peringatan banjir yang efisien dengan tetap mempertimbangkan biaya produksi telah menjadi misi yang berarti bagi banyak orang peneliti dan manufaktur. [1] [2].

Pada percobaan ini yang menarik adalah penggunaan teknologi Internet of Thing (IoT) untuk peringatan dini banjir. IoT mampu menyediakan interkoneksi global perangkat dan objek, sensor, ponsel, aktuator, komputer, dan lain lain [3] dan [4]. Sehingga diberbagai negara banyak peneliti memanfaatkan IoT menjadi solusi permasalahan [5],[6],[7]-[19]. Pemanfaatan teknologi IoT juga dapat dimanfaatkan untuk memonitor suhu ruangan server sehingga memudahkan pekerjaan teknisi computer [20]. Untuk mengetahui seberapa cepat proses pengiriman data dari transmitter menuju receiver dengan menggunakan modul Wi-Fi ESP8266 apabila modul ini dijadikan medium transmisi data yang terhubung pada saluran serial data Arduino Mega [21], karena ekosistem remote sensor $I o T$ adalah pengembangan dari $\mathrm{Wi}-\mathrm{Fi}$ ESP8266 .

Penetitian tentang permasalahn banjir juga banyak dilakukan dengan mulai dari cara akusisi data ketinggian permukaan air hingga pengolahan datanya dengan cara metode komputasi tingkat lanjut [22],[23], dan [24].

Pada percobaan prototipe ini, untuk menpatkan ketinggian permukaan air kanal menggunakan sensor jarak dengan prinsisp rambatan gelombang ultrasonic pada media udara. Gelombang ultrasonic pada banyak penelitian mampu untuk digunakan untuk mengetahui jarak suatu obyek [25],[26],[27]-[30].

Prinsip kerja sensor jarak atau range finder adalah memanfaatkan lama waktu rambatan gelombang suara ultrasonic dengan frekwensi $40 \mathrm{kHz}$. Lama perjalanan rambatan gelombang suara mulai dari pengirim hingga kembali ke penerima setelah dipantulkan obyek. Dengan membagi dua waktu tempuh rambatan gelombang suara ini 
maka akan diketahui jarak suatu obyek terhadap sensor [31], sehingga sensor jenis ini dapat digunakan sebagai sensor ketinggian permukaan air.

NodeMCU ESP8266 adalah firmware open-source berbasis Lua sekaligus development board yang dirancang khusus untuk aplikasi-aplikasi berbasis IoT [32]. Blynk adalah salah satu platform IoT yang menarik, karena dapat digunakan untuk menbangun aplikasi IoT tanpa harus menggunan Personal Computer $(P C)$ atau Laptop dan mendukung semua file pustaka untuk beragam hardware, salah satunya yang didukung adalah board NodeMCU [33].

\section{Metode Penelitian}

Berikut ini adalah metode yang ditawarkan pada percobaan prototipe peringatan dini banjir yang terdiri dari enam (6) tahapan yang diuraikan sebagai berikut. Pada penelitian ini tahapan pertama adalah pemanfaatan alat bantu berupa peta yang berasal dari google maps berfungsi sebagai penentu letak koordinat pasangan lintang dan bujur bumi untuk penempatan sensor ketinggian permuakaan air kanal. Tahap kedua yaitu mengukur lebar kanal dengan posisi tegak lurus terhadap sisi tepi kanal. Selanjutnya pada tahap ketiga menentukan ruang kerja sensor ketinggian pada permukaan air kanal berdasar pada lembar teknis sensor, permukaan badan jalan sebagai referensi level 0 , dengan mengambar potongan melintang pada kanal, yang berhubungan dengan karakteristik.

Tahap keempat adalah merancang model keputusan untuk beberapa keadaan level atau tingkat ketinggian permukaan air kanal. Ketinggian permukaan air kanal berhubungan dengan asumsi kendaraan bermotor yang melintasi banjir.langkah selanjutnya di tahap kelima yaitu membuat diagram blok sistem peringatan dini banjir menggunakan teknologi IoT dan merancang algoritma. Di tahap terakhir adalah melakukan implementasi teknologi IoT pada Android smart-phone dan embedded system. Metode penelitian diperlihatkan pada gambar 1. dalam bentuk diagram.

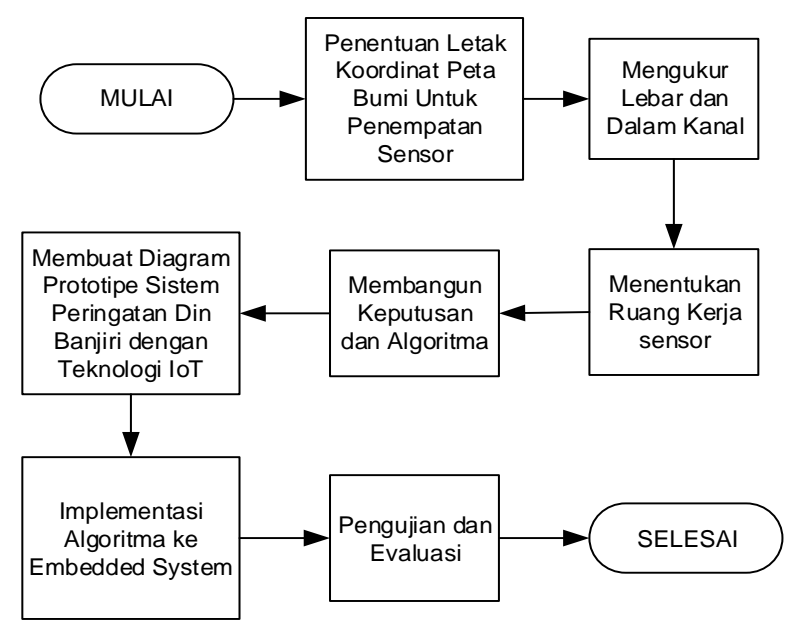

Gambar 1. Diagram metode penelitian

\section{A. Bahan Penelitian}

Obyek penelitian adalah ketinggian permukaan air pada sisi Jalan Jenderal Ahmad Yani, yang terletak pada koordinat dalam satuan sudut yaitu lintang selatan di $0^{\circ} 32 ' 23.8^{\prime \prime}$ dan bujur timur di $117^{\circ} 07^{\prime} 39.5^{\prime \prime}$. letak posisi titik obyek ditunjukkan pada

2 dengan menggunakan peta Google. Pada sepanjang jalan Jenderal Ahmad Yani kerap terjadi luapan air dari kanal yang terletak pada sisi-sisinya. Luapan air terjadi pada saat debet air menigkat melampaui kemampuan kanal. Peningkatan debet air disebabkan oleh perpaduan curah hujan dan durasi hujan, yang mana dalam penelitian ini belum digali secara mendalam tentang informasi ilmiahnya.

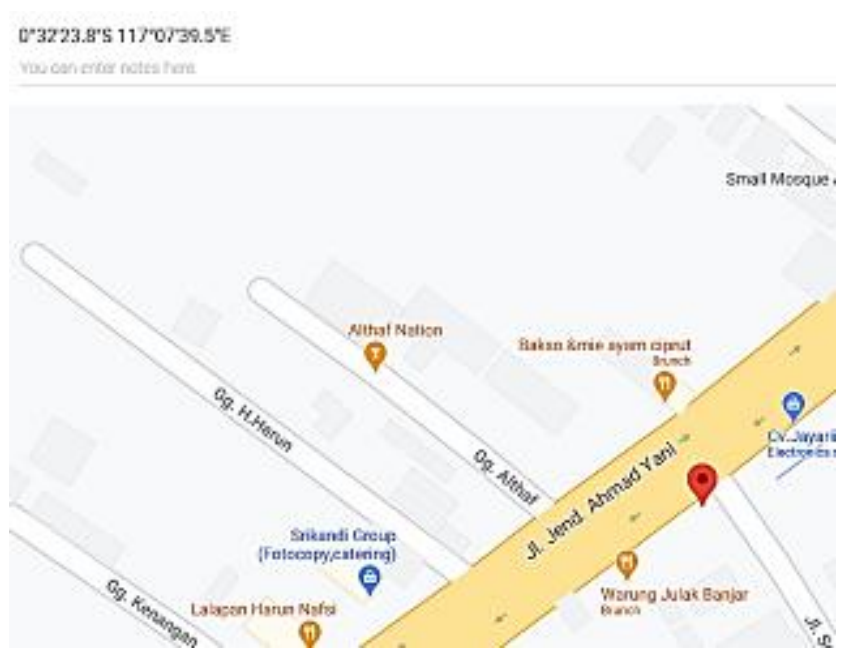

Gambar 2. Letak obyek yang dijadikan titik obyek kasus penelitian ditunjukkan

Berdasarkan letak titik pada kanal seperti

2, dapat dilakuan pendekatan untuk mengetahui lebar kanal pada posisi melintang. Dengan cara merubah tampilan

2 kedalam tampilan satelit agar tampilan citra sisi tepi kanal terlihat seperti ditunjukkan Gambar 3. Tampilan citra satelit posisi pengukuran lebar kanal. Pengukuran lebar kanal dengan cara, membuat pengukuran yang posisinya tegak lurus dengan sisi tepi kanal. Pengukuran secara tegak lurus bertujuan agar kesalahan ukur lebih kecil dibandingkan dengan pengukuran yang tidak tegak lurus dengan sisi kanal. Hasil pengukuran dengan menggunakan alat ukur peta Google, didapatkan lebar kanal posisi melintang adalah sebesar 8 meter, dan garis sepanjang 8 meter ini sejajar dengan jembatan yang posisinya berada disebelah kanannya. Hasil pengukuran dengan alat ukur Google juga dapat dilihat pada Error! Reference source not found. 3 . 


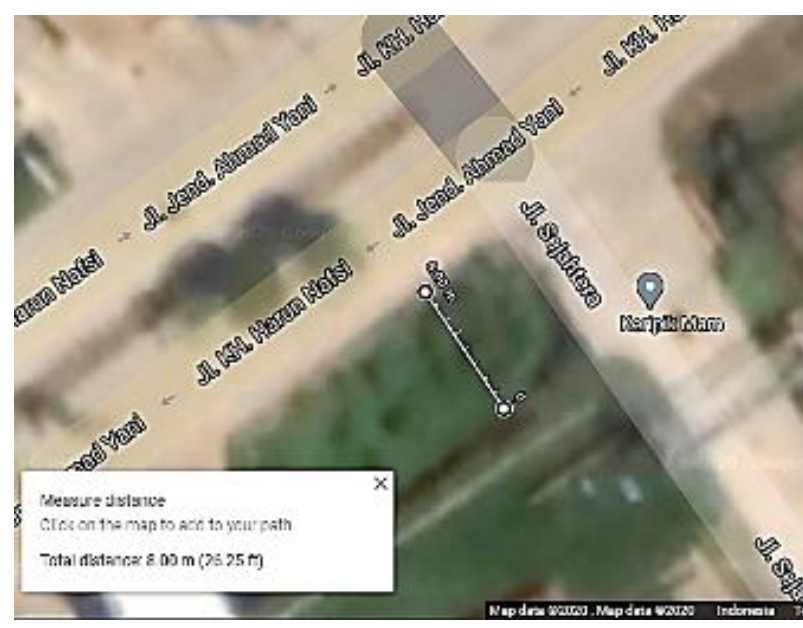

Gambar 3. Tampilan citra satelit posisi pengukuran lebar kanal

Berdasarkan letak titik pada kanal seperti ditunjukkan

2, dapat dilakuan pendekatan untuk mengetahui ruang kerja sensor. Dengan cara merubah tampilan

3 kedalam tampilan jalan yang ditunjukkan pada 4 . Pada posisi tampilan jalan dapat diketahui situasi kanal posisi melintang yang ditunjukkan Error! Reference source not found.4 dengan cara melakukan penalaan, sehingga didapatkan posisi melintang yang sejajar dengan permukaan jembatan. Tautan hasil penalaan posisi potongan melintang yang sejajar dengan jembatan adalah https://www.google.com/maps/@_

$0.5398975,117.1277615,3 \mathrm{a}, 46.1 \mathrm{y}, 237 \mathrm{~h}, 84.8 \mathrm{t} / \mathrm{data}=! 3 \mathrm{~m} 6 ! 1$ e1!3m4!1sfV2FxRfvb6Z8uAXqlepusQ!2e0!7i16384!8i81 92.

Setelah mendapatkan posisi tampilan jalan yang sejajar dengan jembatan Jalan Sejahtera, langkah selanjutnya mencari gambar kanal potongan melintang. Untuk tujuan mencari gambar kanal potongan melintang terlebih dahulu mengukur tinggi permukaan air kanal berdasar pada Error! Reference source not found.5. Untuk mengetahui tinggi permukaan air digunakan garis-garis bantu, agar mendapatkan dua garis yang saling tegak lurus. Dua garis yang saling tegak lurus tersebut tampak pada gambar 5, yaitu garis warna putih dengan label 5.6 meter dan garis dengan label 1.048 meter. Nilai pada label garis tersebut didapatkan dari pengukuran citra Error! Reference source not found.5 dengan menggunakan Microsoft Visio dengan skala gambar 1 banding 50. Garis dengan label $6.5 \mathrm{~m}$ adalah ukuran lebar kanal posisi melintang dan garis dengan label $1.048 \mathrm{~m}$ adalah jarak antara tinggi permukaan Jalan Jenderal Ahmad Yani dengan permukaan air pada kanal.

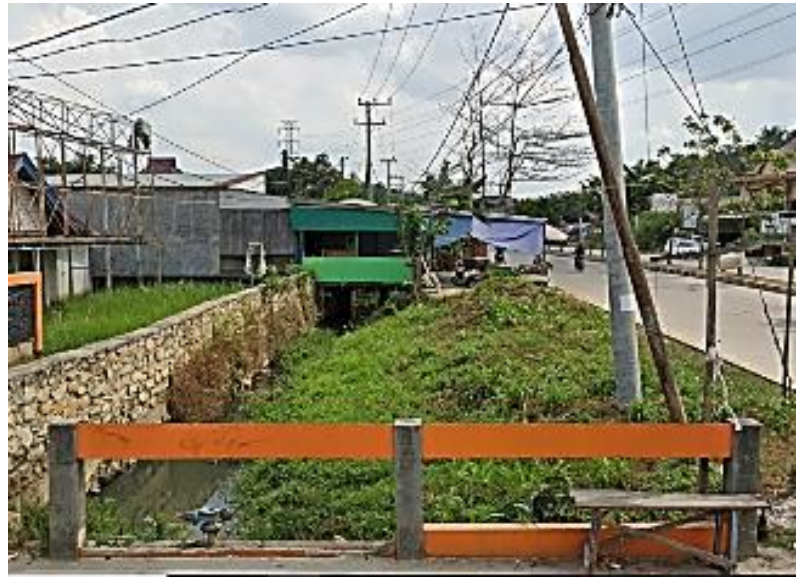

Gambar 4. Tampilan jalan pada peta google untuk mengetahui ruang kerja sensor

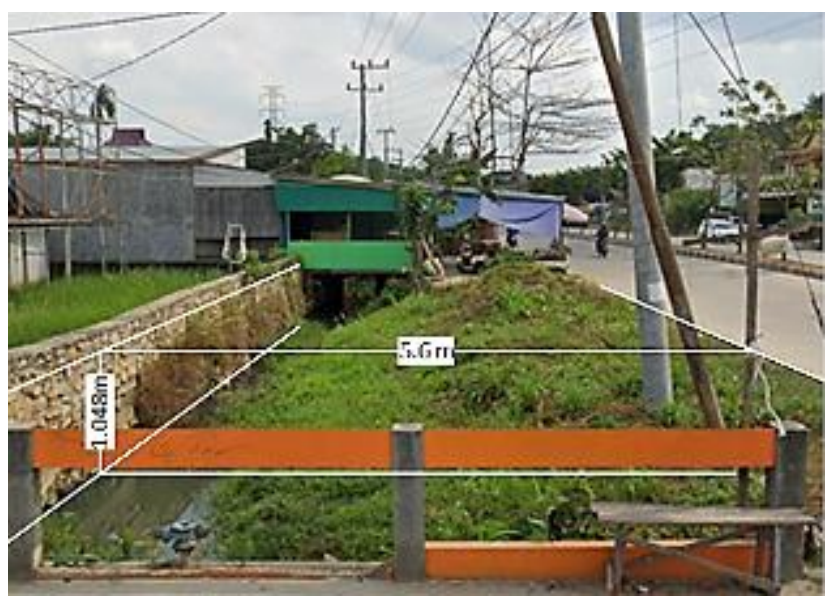

Gambar 5. Penggunaan garis bantu untuk mendapatkan rasio geometri

Untuk medapatkan jarak nyata antara tinggi permukaan jalan raya dengan permukaan air pada kanal, maka dilakukan persamaan antara garis hasil pengukuran peta google dengan garis hasil pengukuran Microsoft Visio. Persamaan Error! Reference source not found. adalah persamaan antara garis hasil pengukuran peta google dengan garis hasil pengukuran Microsoft Visio.

$$
d-\frac{l \times d_{1}}{l_{1}}
$$

Dimana:

$l_{1} \quad$ Lebar kanal Microsoft Visio

$l \quad$ Lebar kanal peta Google

$d_{1} \quad$ jarak antara tinggi permukaan Jalan dengan permukaan air Microsoft Visio

$d \quad$ jarak antara tinggi permukaan Jalan dengan permukaan air peta Google 


\section{HASIL DAN PEMBAHASAN}

\section{A. Hasil Perancangan dan Algoritma}

Permukaan badan jalan dijadikan referensi titik $0 \mathrm{~cm}$, yang ditandai oleh garis putus-putus melintang horizontal, yang ditunjukkan Error! Reference source not found. Pada penelitian ini sensor jarak yang digunakan adalah sensor jarak dengan seri JSN-SR04T-2.0 dengan daerah pengukuran $20 \mathrm{~cm}$ hingga $600 \mathrm{~cm}$ dengan menggunakan pantulan Ultrasonic. JSN-SR04T-2.0 adalah sensor tahan air ( Waterproof Range Finder ). JSN-SR04T-2.0 memiliki daerah sudut pengukuran sebesar $75^{\circ}$. Sudut pengukuran $75^{\circ}$ dijadikan dasar penentuan letak sensor pada daerah kanal, yang tampak pada Error! Reference source not found.6. Cara meletakkan sensor diatas kanal adalah ditata sedemikian rupa agar Sudut pengukuran $75^{\circ}$ tidak terganggu oleh obyek lain. Obyek yang dijadikan target utama pada percobaan ini adalah permukaan air dalam kanal. Berdasarkan situasi penampang potongan kanal pada Error! Reference source not found., jari-jari busur $r$ berada pada nilai $300 \mathrm{~cm}$. Sehingga tinggi maksimum posisi muka sensor $h$ berada pada ketinggian $150 \mathrm{~cm}$ terhadap permukaan badan jalan raya. Berdasar datasheet JSN-SR04T-2.0, daerah yang tidak bisa diukut berada pada jari-jari $r$ lebih kecil sama dengan $20 \mathrm{~cm}$, sehingga ketinggian $h$ yang bisa diukur pada penelitian ini adalah $130 \mathrm{~cm}$. Model keputusan peringaran dini banjir direpresentasikan pada bagian sisi kiri Error! Reference source not found.6, disitu terdapat sekala tingkat ketinggian air dari negative $150 \mathrm{~cm}$ hingga positive $130 \mathrm{~cm}$. Tingkat ketinggian dengan label normal warna hijau diberi rentang nilai $-150 \mathrm{~cm}$ hingga $0 \mathrm{~cm}$. Tingkat ketinggian dengan label banjir warna kuning diberi rentang nilai $0 \mathrm{~cm}$ hingga $30 \mathrm{~cm}$. Tingkat ketinggian dengan label banjir warna merah diberi rentang nilai $30 \mathrm{~cm}$ hingga $130 \mathrm{~cm}$. Tingkat ketinggian dengan label banjir warna kuning memiliki asumsi bahwa, dengan tingkat ketinggian sampai $30 \mathrm{~cm}$ kendaraan bermotor masih bisa melalui banjir. Tingkat ketinggian dengan label banjir warna merah memiliki asumsi bahwa, dengan tingkat ketinggian lebih besar dari $30 \mathrm{~cm}$ berbahaya bagi kendaraan bermotor.

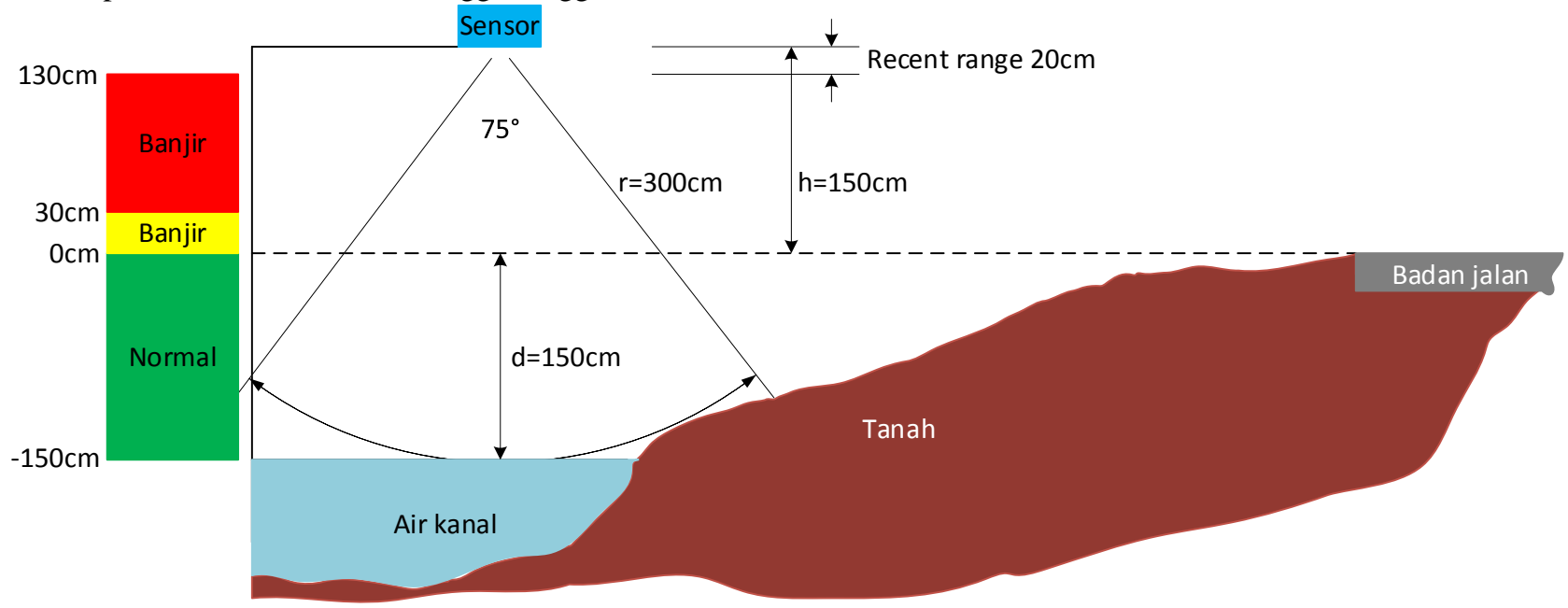

Gambar 6. Potongan kanal posisi melintang

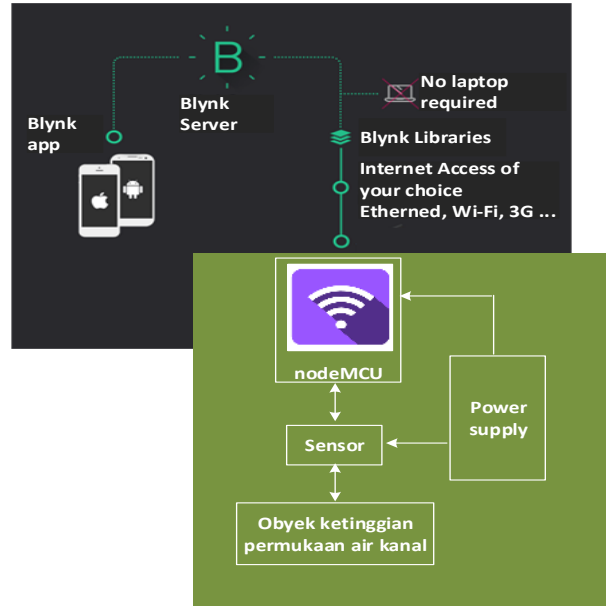

Gambar 7. Diagram blok system peringatan dini banjir menggunakan teknologi IOT
Blok berwarna hijau yang tampak pada Error! Reference source not found.7 adalah system yang dirakit sesuai kebutuhan. Penyedia layanan komputasi awan yang digunakan pada percoabaan ini adalah Blynk. Development board untuk menanam system peringantan dini banjir menggunakan nodeMCU, yang mana nodeMCU adalah microcontroller berbasis IoT. nodeMCU terhubung dengan sensor melalui sinyal dua arah, yaitu sinyal triger yang dikirimkan oleh nodeMCU menuju sensor, dan sinyal echo yaitu sinyal yang diterima oleh nodeMCU dari sensor. Hubungan blok sensor dengan blok obyek tingkat ketinggian air yang variatif juga terjadi dua arah, yaitu sinyal suara sebanyak 8 kali panjang gelombang dengan frekwensi $40 \mathrm{kHz}$ dikirimkan melalui transmitter kepermukaan air yang kemudian ditunggu pantulannya oleh receiver sensor. Blok power supply berfungsi memberi daya listrik kepada tiga blok agar dapat dapat beroperasi, yang mana tegangan yang digunakan adalah 5 
Volt arus searah sebesar $500 \mathrm{~mA}$. Pada blok dengan latar hitam adalah bagian yang telah disediakan oleh layanan Blynk, yang mana posisi user sebagai pengguna berada disini.

TABEL I

HASIL PENGAMATAN PERCOBAAN

\begin{tabular}{|c|c|c|c|}
\hline No & \begin{tabular}{|c|} 
Jarak \\
Sensor \\
dengan \\
obyek \\
$(\mathrm{cm})$ \\
\end{tabular} & $\begin{array}{c}\text { Display } \\
\text { hasil } \\
\text { komputasi } \\
\text { (cm) }\end{array}$ & $\begin{array}{l}\text { Interupsi Peringatan pada } \\
\text { tampilan layar Smartphone }\end{array}$ \\
\hline 1 & 300 & -150 & Tidak ada \\
\hline 2 & 290 & -140 & Tidak ada \\
\hline 3 & 280 & -130 & Tidak ada \\
\hline 4 & 200 & -50 & Tidak ada \\
\hline 5 & 190 & -40 & Tidak ada \\
\hline 6 & 180 & -30 & Tidak ada \\
\hline 7 & 170 & -20 & Tidak ada \\
\hline 8 & 151 & -1 & Tidak ada \\
\hline 9 & 150 & 0 & Tidak ada \\
\hline 10 & 149 & 1 & Level air diatas jalan! \\
\hline 11 & 140 & 10 & Level air diatas jalan! \\
\hline 12 & 120 & 30 & Level air diatas jalan! \\
\hline 13 & 119 & 31 & Level air Berbahaya diatas $30 \mathrm{~cm}$... ! \\
\hline 14 & 110 & 40 & Level air Berbahaya diatas $30 \mathrm{~cm} . .$. ! \\
\hline 15 & 40 & 110 & Level air Berbahaya diatas $30 \mathrm{~cm} \ldots$... \\
\hline 16 & 30 & 120 & Level air Berbahaya diatas $30 \mathrm{~cm}$... ! \\
\hline 17 & 21 & 129 & Level air Berbahaya diatas $30 \mathrm{~cm} \ldots$... \\
\hline 18 & 20 & nilai acak & Terkadang tidak sesuai \\
\hline 19 & 10 & nilai acak & Terkadang tidak sesuai \\
\hline 20 & 0 & nilai acak & Terkadang tidak sesuai \\
\hline
\end{tabular}

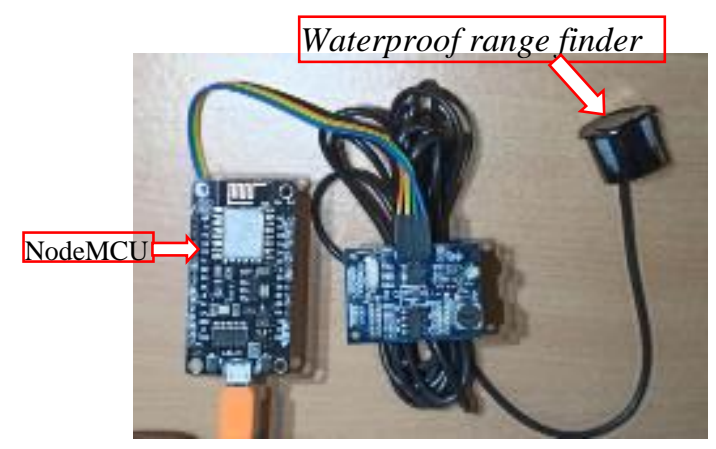

Gambar 8. Rangkaian percobaan

Gambar. 8 adalah rangkaian percobaan yang digunakan untuk mendapat nilai nilai variable jarak tegak lurus sensor dengan obyek datar, yang ditampilkan pada Tabel 1. Percobaan dilakukan dengan syarat area bebas sensor adalah $75^{\circ}$ dan jarak tegak lurus obyek datar dengan sensor terjauh adalah $300 \mathrm{~cm}$, yang mengacu pada Gambar. 6 . Rentang jarak maksimum $300 \mathrm{~cm}$ digunakan dengan asumsi tinggi permukaan air kanal adalah $-150 \mathrm{~cm}$ terhadap permukaan jalan raya. Karena berdasar lembar data JSNSR04T-2.0, hasil pengukuran jarak sensor ini mendekati linier terhadap setengah waktu tempuh gelombong ultrasonic yang dipantulkan kearah obyek datar. Sehingga pengambilan data uji dilakukan untuk keperluan kinerja fungsi interupsi peringatan dini banjir. Dengan alasan ini, maka pengambilan perubahan variabel jarak pada Tabel 1 tidak seragam sebesar $1 \mathrm{~cm}$ atau $10 \mathrm{~cm}$. Misalkan pada data nomor baris 12 adalah $120 \mathrm{~cm}$ dan nomor baris 13 adalah 119 selisih perubahanya sebesar $1 \mathrm{~cm}$. Perubahan sebesar 1 $\mathrm{cm}$ ini untuk menguji fungsi pada flowchart pengambilan keputusan pada Gambar. 10, yang berbunyi "Apakah tingkat ketinggian permukaan air lebih dari $30 \mathrm{~cm}$ ?". Sedangkan pada data nomor baris 1 adalah $300 \mathrm{~cm}$ dan nomor baris 2 adalah 290 selisih perubahanya sebesar 10 $\mathrm{cm}$. Perubahan sebesar $10 \mathrm{~cm}$ diasumsikan masih jauh atau tidak melalui dari nilai-nilai jarak yang dijadikan keputusan interupsi peringatan kepada pengguna. Dari hasil percobaan, nilai jarak terdekat yang bisa di ukur adalah 21 $\mathrm{cm}$ atau ketinggian air $129 \mathrm{~cm}$. Batasan nilai ini disebabkan karaktesistik sensor yang hanya mampu membaca jarak paling dekat sekitar $20 \mathrm{~cm}$ atau jika dikonversi dalam nilai ketinggian air adalah $130 \mathrm{~cm}$ diatas permukaan jalan.

Algoritma yang digunakan pada sistem peringatan dini banjir menggunakan model pemrograman berbasis peristiwa yang ditunjukkan Error! Reference source not found.9. Sikulus komputasi yang dilakukan dijadwalkan setiap peristiwa pewaktu 500 mili detik. Prosedur proses peringatan dini banjir pada percobaan ini ditunjukkan pada Error! Reference source not found. 10.

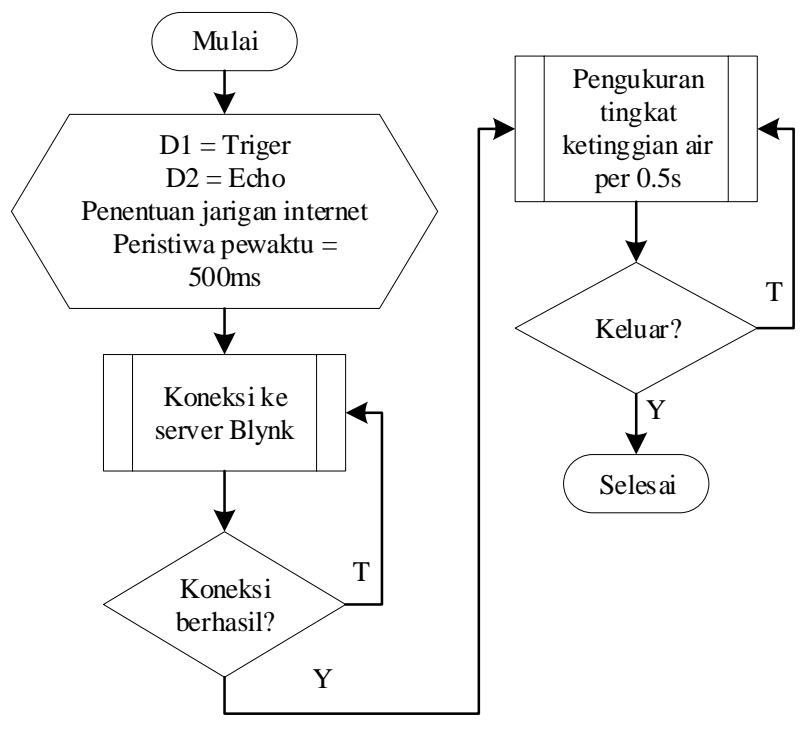

Gambar 9. Proses pemrograman berbasis pariwisata 


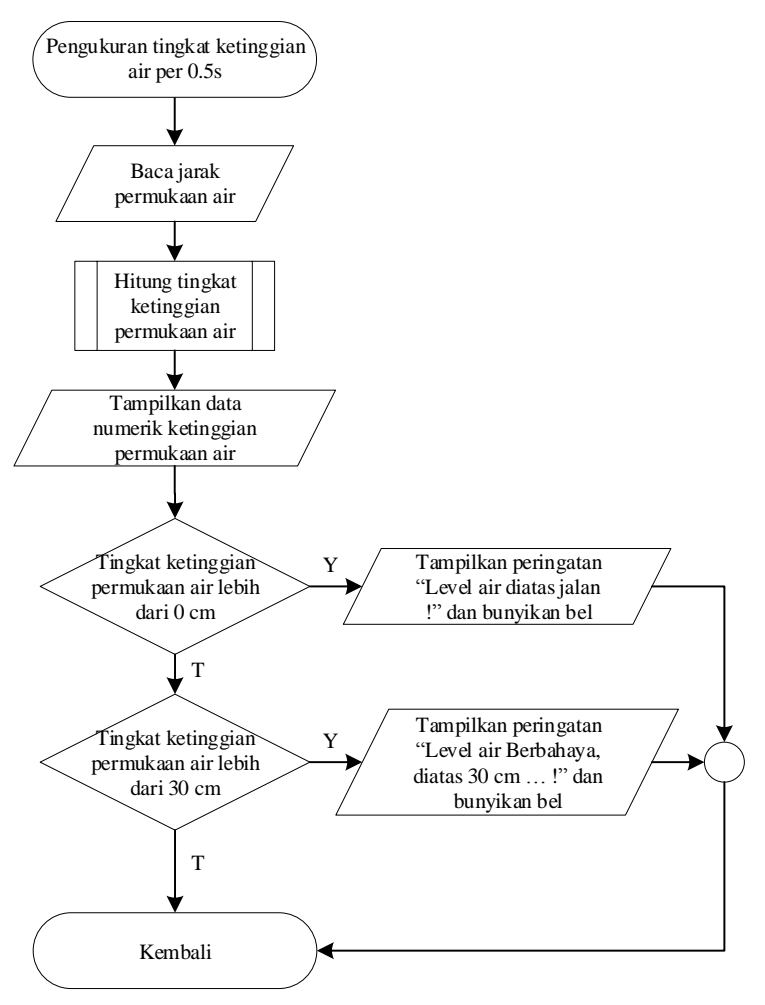

Gambar 20. Prosedur proses peringatan dini banjir

\section{B. Display Deteksi Dini Banjir}

Dengan memanfaatkan piranti mobile berbasis android, hasil sensor cerdas yang diputuskan menjadi keputusan peringatan dini dapat ditampilkan oleh display yang ditunjukan gambar 11 sampai dengan gambar 14 .

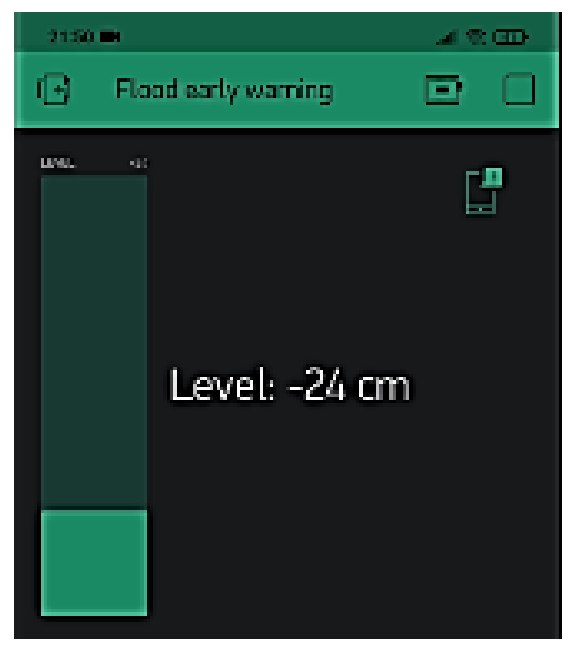

Gambar 31. Nilai level dibawah permukaan jalan

Error! Reference source not found.11 menampilkan saat Level bernilai negatif $24 \mathrm{~cm}$, yang berarti posisi permukaan air dibawah permukaan jalan.

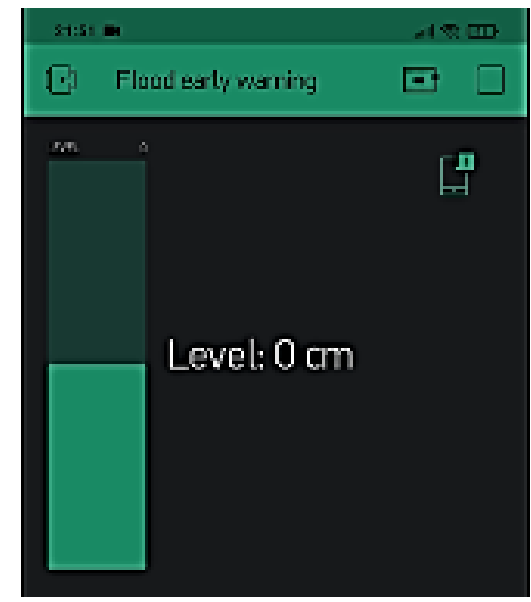

Gambar 42. Nilai level sama dengan permukaan jalan

Pada tampilan Error! Reference source not found.2 Level bernilai $0 \mathrm{~cm}$, yang artinya tinggi permukaan air sama dengan tinggi permukaan jalan.

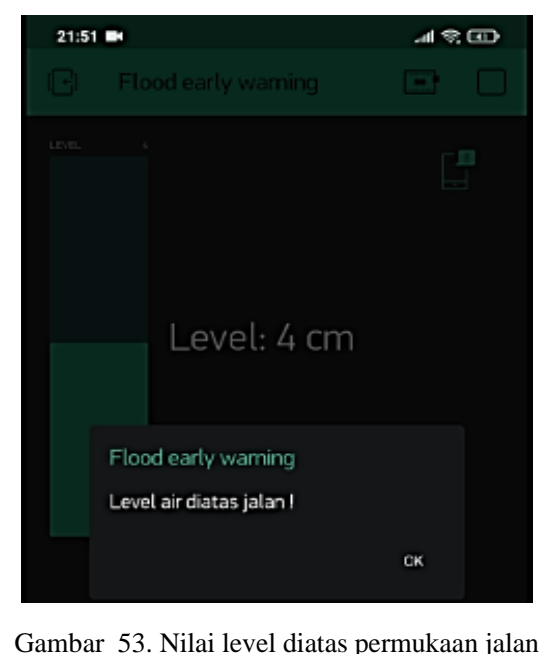

Pada tampilan Error! Reference source not found. 3 Level bernilai $3 \mathrm{~cm}$, yang artinya tinggi permukaan air diatas permukaan jalan, pada posisi ini peringatan muncul berupa bunyi bel bersamaan dengan muncul teks peringatan. 


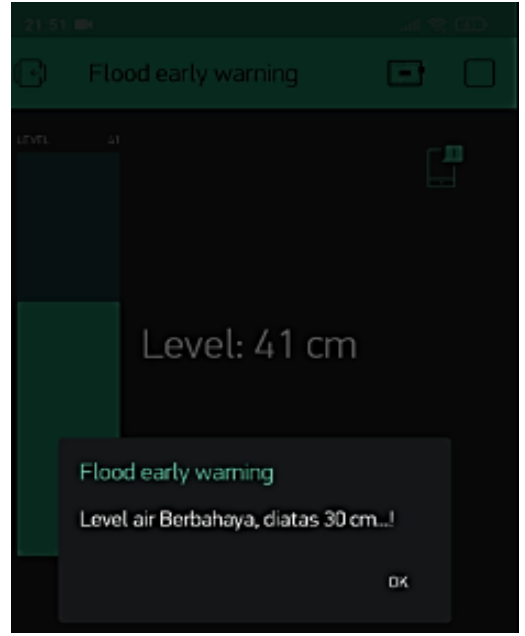

Gambar 64. Nilai level diatas permukaan jalan

Demikian pula pada tampilan Error! Reference source not found. 4 Level bernilai $41 \mathrm{~cm}$, yang artinya permukaan air diatas permukaan jalan lebih dari $30 \mathrm{~cm}$.

Hasil perngamatan perubahan ketinggian permukaan air pada tampilan layar handphone android yang tampak pada Error! Reference source not found.1 sampai Error! Reference source not found.4, terlihat bahwa tingkat ketinggian permukaan air direpresentasikan dengan variabel Level berwarna hijau, dan sebuah label Level dengan tampilan data numerik berwarna putih.

\section{KESIMPULAN}

Sistem peringatan dini banjir mampu menampilkan representasi data dalam bentuk level vertikal dan data numerik dengan tinggkat ketinggian air paling rendah adalah $-150 \mathrm{~cm}$ dan paling tinggi $130 \mathrm{~cm}$, dengan representasi nilai $0 \mathrm{~cm}$ apabila tingkat ketinggian permukaan air sejajar dengan permukaan badan jalan .

Peringatan berupa bunyi bel bersama teks "Level air diatas jalan!" apabila nilai tingkat ketinggian air lebih dari $0 \mathrm{~cm}$, dan bunyi bel bersama teks "Level air Berbahaya, diatas $30 \mathrm{~cm}$...!" apabila nilai tingkat ketinggian air memenuhi batas maksimal. dimana pembaharuan data numerik tingkat ketinggian permukaan air kanal terjadi setiap 500 mili detik.

Penerapan algoritma penentu keputusan berdasarkan peristiwa yang dikombinasikan dengan konversi dari data peta satelit sebagai validasi penempatan sensor berhasil di implementasikan pada prototipe peringatan dini banjir berbasis $I o T$ Untuk selanjutnya peneliti akan melanjutkan penelitian ini dari sisi komunikasi data sehingga prototype ini akan menjadi produk teknologi tepat guna yang dapat dimanfaatkan masyarakat umum.

\section{UCAPAN TERIMA KASIH / ACKNOWLEDGMENT}

Peneliti mengucapkan terimakasih kepada Modern Computing \& Robotic System Research Center Politeknik Negeri Samarinda dan Hibah Unit Penelitian \& Pengabdian Masyarakat Politeknik Negeri Samarinda DIPA 2020.

\section{REFERENSI}

[1] H. N. Do, M.-T. Vo, V.-S. Tran, P. V. Tan and C. V. Trinh, "An early flood detection system using mobile networks," in International Conference on Advanced Technologies for Communications (ATC), Ho Chi Minh, 2015.

[2] G. Megha, D. P. Babasaheb, S. Manojkumar and D. Akshay, "Early Flood Detection System using Android Application," International Journal of Engineering Research \& Technology, vol. 8, no. 7, 2019.

[3] A. A. Jaafar, K. H. Sharif, M. I. Ghareb and D. N. A. Jawawi, "Internet of Thing and Smart City: State of the Art and Future Trends," in International Conference on Computer, Communication and Computational Sciences (IC4S), Patong Phuket, 2017.

[4] H. Hassan, R. A. Jamaluddin and F. M. Marafa, "Internet of Thing (IoT) Smart Home Systems: Conceptual Ethical Framework for Malaysian Developers," in International Visual Informatics Conference (IVIC), Bangi, 2019.

[5] W. Li, T. Logenthiran, V.-T. Phan and W. L. Woo, "Implemented IoT-Based Self-Learning Home Management System (SHMS) for Singapore," IEEE Internet of Things Journal, vol. 5, no. 3, pp. 2212 - 2219, 2018.

[6] M. A. Fabrício, F. H. Behrens and D. Bianchini, "Monitoring of Industrial Electrical Equipment using IoT," IEEE Latin America Transactions, vol. 18, no. 8, pp. 1425 - 1432, 2020.

[7] K. Tong Lee and H. Kit Mun, "Real-time power monitoring using field-programmable gate array with IoT technology," IET Science, Measurement \& Technology, vol. 13, no. 6, pp. 931-935, 2019.

[8] A. O. Akmandor, H. YIN and N. K. Jha, "Smart, Secure, Yet Energy-Efficient, Internet-of-Things Sensors," IEEE Transactions on Multi-Scale Computing Systems, vol. 4, no. 4, pp. 914 - 930, 2018 .

[9] F. Wu, J.-M. Redouté and M. R. Yuce, "WE-Safe: A Self-Powered Wearable IoT Sensor Network for Safety Applications Based on LoRa," IEEE Access, vol. 6, pp. 2169-3536, 2018.

[10] J. Khan, J. P. Li, B. Ahamad, S. Parveen, A. U. Haq, G. A. Khan and A. K. Sangaiah, "SMSH: Secure Surveillance Mechanism on Smart Healthcare IoT System With Probabilistic Image Encryption," IEEE Access, vol. 8, pp. 15747 - 15767, 2020.

[11] S. S. Sarmah, "An Efficient IoT-Based Patient Monitoring and Heart Disease Prediction System Using Deep Learning Modified Neural Network," IEEE Access, vol. 8, pp. 135784 - 135797, 2020.

[12] A. Venkatanarayanan, A. Vijayavel, A. Rajagopal and P. Nagaradjane, "Design of sensor system for air pollution and human vital monitoring for connected cyclists," IET Communications, vol. 13 , no. 19 , pp. $3181-3186,2019$.

[13] K. Muhammad, R. Hamza, J. Ahmad, J. Lloret, H. Wang and S. W Baik, "Secure Surveillance Framework for IoT Systems Using Probabilistic Image Encryption," IEEE Transactions on Industrial Informatics, vol. 14, no. 8, pp. 3679 - 3689, 2018.

[14] J. Díaz, J. E. Pérez, Lopez-Peña, M. A., G. A. Mena and A. Yagüe, "Self-Service Cybersecurity Monitoring as Enabler for DevSecOps," IEEE Access, vol. 7, pp. 100283 - 100295, 2019.

[15] S. Jacob, M. Alagirisamy, V. G. Menon, B. M. Kumar, N. Z Jhanjhi, V. Ponnusamy, P. G. Shynu and V. Balasubramanian, "An Adaptive and Flexible Brain Energized Full Body Exoskeleton With IoT Edge for Assisting the Paralyzed Patients," IEEE Access, vol. 8, pp. 100721 - 100731, 2020.

[16] A. Celesti, A. Galletta, L. Carnevale, M. Fazio, A. Lay-Ekuakille and M. Villari, "An IoT Cloud System for Traffic Monitoring and Vehicular Accidents Prevention Based on Mobile Sensor Data Processing," IEEE Sensors Journal, vol. 18, no. 12, pp. 4795 - 4802 2018

[17] S. S. Chakkaravarthy, D. Sangeetha, M. V. Cruz, V. Vaidehi and B. Raman, "Design of Intrusion Detection Honeypot Using Social Leopard Algorithm to Detect IoT Ransomware Attacks," IEEE Access, vol. 8, pp. 169944 - 169956, 2020.

[18] Q. P. Ha, S. Metia and M. D. Phung, "Sensing Data Fusion for Enhanced Indoor Air Quality Monitoring," IEEE Sensors Journal, vol. 20, no. 8, pp. 4430-4441, 2020.

[19] A. O. Akmandor, o. YINH and N. K. Jha, "Smart, Secure, Yet Energy-Efficient, Internet-of-Things Sensors," IEEE Transactions on Multi-Scale Computing Systems, vol. 4, no. 4, pp. 914-930, 2018 
[20] Periyaldi, A. Wajiansyah and A. B. W. Putra, "Implementasi Sistem Monitoring Suhu Ruang Server Satnetcom Berbasis Internet Of Things (IOT) Menggunakan Protokol Komunikasi Message Queue Telemetry Transport (MQTT)," JURNAL TEKNOLOGI TERPADU (JTT), vol. 6, 2018.

[21] W. M. Kurniawan, Supriadi and A. Wajiansyah, "Performa Komunikasi Arduino Mega2560 Melalui Wifi ESP8266 Pada Baudrate $115200 \mathrm{kbps,"} \mathrm{in} \mathrm{Prosiding} \mathrm{Seminar} \mathrm{Nasional} \mathrm{Ilmu}$ Komputer dan Teknologi Informasi ( SAKTI), Samarinda, 2018.

[22] L. B. L. Santos, T. Carvalho, L. O. Anderson, C. M. Rudorff, V. Marchezini, L. R. Londe and S. M. Saito, "An RS-GIS-Based ComprehensiveImpact Assessment of Floods-A Case Study in Madeira River, Western Brazilian Amazon," IEEE Geoscience and Remote Sensing Letters, vol. 14, no. 9, pp. 1614 - 1617, 2017.

[23] L. Cenci, P. Laiolo, S. Gabellani, L. Campo, F. Silvestro, F. Delogu, G. Boni and R. Rudari, "Assimilation of H-SAF Soil Moisture Products for Flash Flood Early Warning Systems. Case Study: Mediterranean Catchments," IEEE Journal of Selected Topics in Applied Earth Observations and Remote Sensing, vol. 9, no. 12, pp. 5634-5646, 2016.

[24] A. H. Zaji, H. Bonakdari and B. Gharabaghi, "Applying Upstream Satellite Signals and a 2-D Error Minimization Algorithm to Advance Early Warning and Management of Flood Water Levels and River Discharge," IEEE Transactions on Geoscience and Remote Sensing, vol. 57, no. 2, pp. 902-910, 2019.

[25] J.-W. Yoon and T. Park, "Maximizing Localization Accuracy via Self-Configurable Ultrasonic Sensor Grouping Using Genetic Approach," IEEE Transactions on Instrumentation and Measurement, vol. 65, no. 7, pp. 518-1529, 2016.

[26] A. Rocchi, E. Santecchia, F. Ciciulla, P. Mengucci and G. Barucca, "Characterization and Optimization of Level Measurement by an Ultrasonic Sensor System," IEEE Sensors Journal, vol. 19, no. 8, pp. 3077-3084, 2019

[27] A. K. Sahoo and S. K. Udgata, "A Novel ANN-Based Adaptive Ultrasonic Measurement System for Accurate Water Level Monitoring," IEEE Transactions on Instrumentation and Measurement, vol. 69, no. 6, pp. 359-3369, 2020.

[28] S. Shin, M.-H. Kim and S. B. Choi, "Ultrasonic Distance Measurement Method With Crosstalk Rejection at High Measurement Rate," IEEE Transactions on Instrumentation and Measurement, vol. 68, no. 4, pp. 972-979, 2019.

[29] A. Sun, Z. Wu, D. Fang, J. Zhang and W. Wang, "Multimode Interference-Based Fiber-Optic Ultrasonic Sensor for Non-Contact Displacement Measurement," IEEE Sensors Journal, vol. 16, no. 14, pp. 5632-5635, 2016

[30] R. Kusche, F. John, M. Cimdins and H. Hellbrück, "Contact-Free Biosignal Acquisition via Capacitive and Ultrasonic Sensors," IEEE Access, vol. 8, pp. 95629 - 95641, 2020.

[31] B. d. Bakker, "Waterproof JSN-SR04T Ultrasonic Distance Sensor with Arduino Tutorial," 5 March 2020. [Online]. Available: https://www.makerguides.com. [Accessed 5 August 2020].

[32] Components101, "NodeMCU ESP8266," 2 April 2020. [Online]. Available: https://components101.com. [Accessed 5 March 2020].

[33] Blynk, "How Blynk Works," 5 March 2020. [Online]. Available: https://docs.blynk.cc. [Accessed 6 March 2020]. 